\title{
Territórios epistemológicos do Real nas imagens esféricas do dispositivo VR360
}

\author{
Alberto Greciano \& Daniela Zanetti*
}

Resumo: O presente trabalho procura desenvolver uma reflexão crítica sobre as possibilidades estéticas do documentário ao se expandir nos espaços de imersão atmosférica e interação em rede do dispositivo VR $360^{\circ}$. Na conjuntura dessa plataforma digital se projeta um espaço de intercomunicação factual e afetivo que abre possibilidades para produzir uma assimilação transformativa do conhecimento.

Palavras-chave: documentário; imagem esférica; VR360; interface; imersão; interação; conhecimento; pensamento.

Resumen: El presente trabajo intenta desarrollar una reflexión crítica sobre las posibilidades estéticas del documental al expandirse en los espacios de inmersión atmosférica e interacción en red del dispositivo VR $360^{\circ}$. En la coyuntura de esa plataforma digital se proyecta un espacio de intercomunicación factual y afectivo que abre posibilidades para producir una asimilación transformativa del conocimiento.

Palabras clave: documental; imagen esférica; VR $360^{\circ}$; interfaz; inmersión; interacción; conocimiento; pensamiento.

\begin{abstract}
The present work seeks to develop a critical reflection on the aesthetic possibilities of the documentary as it expands in the spaces of atmospheric immersion and network interaction of the VR $360^{\circ}$ device. At the juncture of this digital platform, a factual and affective intercommunication space is projected that opens possibilities to produce a transformative assimilation of knowledge.

Keywords: documentary; spherical image; VR $360^{\circ}$; interface; immersion; interaction; knowledge; thought.
\end{abstract} * Alberto Greciano: Universidade Federal do Espirito Santo (UFES), Pós-doutorando
do Programa de Pós-Graduação em Comunicação e Territorialidades (PósCom),
Grupo de Pesquisas em Cultura Audiovisual e Tecnologia (CAT), CEP 29075-910-
Vitória-ES, Brasil. E-mail: albertogreciano@ gmail.com
Daniela Zanetti: Universidade Federal do Espirito Santo (UFES), Professora Adjunta
do Departamento de Comunicação Social e do Programa de Pós-Graduação em Co-
municação e Territorialidades (PósCom) da Universidade Federal do Espírito Santo
(UFES), CEP 29075-910 - Vitória-ES, Brasil. E-mail: daniela.zanetti@ @mail.com
O presente trabalho de pesquisa foi realizado com apoio do CNPq - Conselho
Nacional de Desenvolvimento Científico e Tecnológico Brasil (167451/2017-0).

Submissão do artigo: 31 de outubro de 2018. Notificação de aceitação: 28 de janeiro de 2019. 
Résumé : Le présent travail cherche à développer une réflexion critique sur les possibilités esthétiques du documentaire au fur et à mesure de son expansion dans les espaces d'immersion atmosphérique et d'interaction réseau du dispositif VR360. À la croisée de cette plate-forme numérique, un espace intercommunautaire factuel et affectif ouvre les possibilités de produire une assimilation transformative du savoir. Mots-clés : documentaire ; image sphérique ; VR $360^{\circ}$; interface ; immersion ; interaction ; connaissance ; pensée.

\section{Introdução}

O século XXI trouxe novas possibilidades tecnológicas que potencializaram a forma como o documentário se conecta com o imaginário, ancorando-se no real. Essa potência encontra na consolidação e ampliação dos suportes de produção e distribuição digital uma aliança para superar as limitações da representação através da narração linear no dispositivo cinematográfico da sala escura. O documentário, ao se expandir no sistema estrutural, sociocultural e cognitivo que supõe a chegada da Interface (Bruno, 2001; Manovich, 2001; Emmerick, 2008; Català, 2010), vem multiplicando suas possibilidades estéticas e políticas em espaços de imersão atmosférica e de interação em rede.

Este trabalho parte do interesse em desenvolver uma reflexão crítica sobre como os documentaristas assumem em suas produções os avanços que a indústria e o mercado das tecnologias audiovisuais estão oferecendo através das novas ferramentas dirigidas a retomar o projeto utópico da realidade virtual. Para elucidar este fenômeno estabelece-se um procedimento metodológico de análise qualitativa a partir de um marco teórico embasado em conceitos estéticos que vão se apresentar através da forma ensaio. O objetivo é entender como o documentário, ao se situar na conjuntura desse mundo visual, já não consiste em focalizar e analisar de uma forma vetorial algum acontecimento ou circunstância isolada, mas sim abrir possibilidades reflexivas sobre a diversidade de condicionantes que envolvem os fatos e sobre as ideias que se desenvolvem ao redor dessa variedade.

Para isso, partimos do princípio apresentado por Català (2017), segundo o qual os elementos e fundamentos que entram em cena com aplicação das tecnologias de realidade virtual em vídeo volumétrico $\left(\mathrm{VR} 360^{\circ}\right)$ permitem efetivar plenamente a capacidade retórica que detém a imagem e, com isso, introduzir movimentos de pensamento. Ou seja, ao adotar esses recursos tecnológicos na busca de uma nova narrativa dramatúrgica, os documentários tem a possibilidade de se inscrevem numa ecologia visual que obrigue e, ao mesmo tempo, ajude aos usuários a pensar de forma distinta. Nesse dispositivo de comunicação já não se propõe um processo mecanicista de transmissão de informações, 
senão que se projeta um espaço de intercomunicação factual e afetivo que abre possibilidades para produzir uma assimilação transformativa do conhecimento.

\section{Um dispositivo dramatúrgico para se aproximar ao real}

A chegada dos equipamentos e formatos das mídias digitais ao ecossistema comunicativo tem provocado uma diversificação do dispositivo cinematográfico através da transformação de suas dimensões primordiais: arquitetônica (as condições de projeção das imagens), tecnológica (a produção, edição, transmissão e distribuição das imagens) e discursiva (decupagem, montagem, etc.) (Parente, 2007, p.3).

Lucilla Calogero (2016) aplica uma série de conceitos agrupados ao redor das três unidades clássicas de análise (espaço, tempo, ação) para apontar as diferenças entre as condições da experiência sensorial que propõem esses entornos virtuais e as dimensões do espaço ilusionista da representação cinematográfica (figura 1).

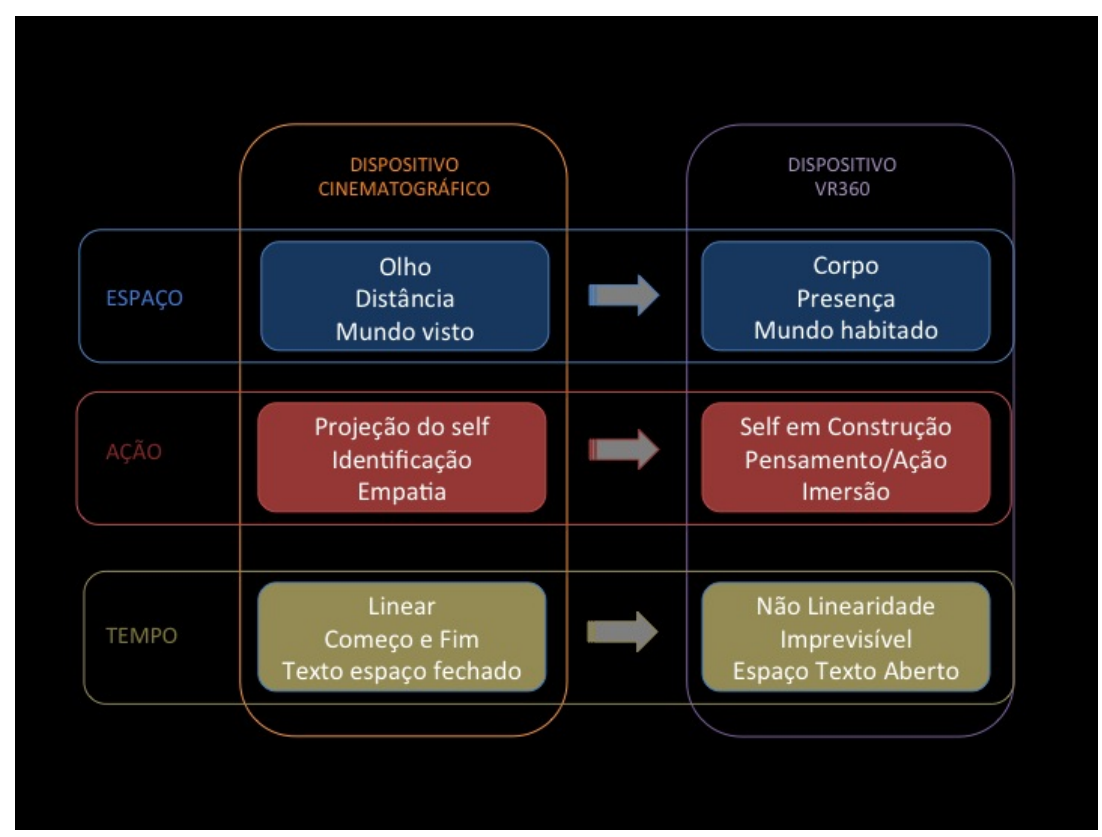

Figura 1

Seguindo o estudo comparativo que ela efetua, entendemos que no dispositivo cinematográfico a experiência do espectador está marcada pelo espaço de um mundo visualizado que, ao estar delimitado pelo quadro (câmera/tela), 
propõe uma prática ocular bidimensional à distância. Esse impulso voyeur, por sua vez, provoca uma suspensão regressiva do sujeito ao se identificar com a representação móvel do outro na superfície da tela, pois o eu do sujeito (self) se projeta na empatia de um corpo duplicado cuja imersão é permanentemente postergada na previsibilidade do texto. Ou seja, na conjuntura deste dispositivo se produz um espaço fechado cuja temporalidade linear provoca que a realidade se abrigue no simulacro da relação dinâmica que se estabelece entre corpo e mundo por meio da sensibilidade, emoção, cognição e ação. Já na experiência imersiva do dispositivo VR $360^{\circ}$ a presença do corpo é singular e se encontra no interior de um ambiente virtual tridimensional. As dinâmicas que regulam esse espaço interface oferecem a impressão de um mundo habitado onde a visão ativa do usuário participante possui o controle do dispositivo. A imersão na temporalidade não linear da imagem provoca que o espaço se converta num texto aberto, aparentemente transparente e imprevisível onde o mundo e o sujeito estão em constante construção através da progressão que produz a mobilidade do usuário em sua interação com a imagem. Esse impulso integrador autodirigido muda as regras do engajamento entre o sujeito e o objeto convertendo os entornos VR $360^{\circ}$ no que Català $(2005,2010,2017)$ define como ecossistemas de pensamento-ação.

Os atuais ambientes VR $360^{\circ}$ supõem um importante salto qualitativo na evolução e consolidação das propostas imersivas aplicadas à imagem. Tentativas que passam pela magia das cavernas platónicas, a poética da taumaturgia, a estereoscópica e a fotografia panorâmica, os panoramas e o sensorama, assim como as diversas propostas dos cineramas e cinemas 3D, ou a simulação da realidade em entornos virtuais lúdicos por meio de avatares. Na atualidade, a computação ubíqua, a explosão dos conteúdos em HTML 5 e a proliferação de produtos de consumo doméstico para produzir e visualizar imagens VR $360^{\circ}$, além de supor um desenvolvimento das mídias também trazem um processo de reformulação do campo midiático. A popularização e consolidação destas tecnologias e componentes no mercado comercial estão configurando um dispositivo de comunicação no qual a dramaturgia e a narrativa adotam uma forma relacional, ou como sugere Gaudenzi (2009), "um mecanismo 'autopoiético' ou organismo vivo"(2009, p. 6), que desvanece a distância entre os sujeitos usuários e os objetos tecnológicos de intermediação. Isto é, essa expansão do cinema ativa um espaço interface para onde confluem o usuário e o planejamento da máquina através de uma imagem fluida que irrompe como uma condensação material entre realidade (sociedade) e imaginário (pensamento). Isso vai contribuir fundamentalmente na transição do seu paradigma, que vai migrar da estética reflexiva das superfícies e das telas para uma pragmática per- 
formativa, estabelecendo-se um marco onde a cognição abandona seu caráter oculocêntrico para se tornar fundamentalmente espaço-temporal.

Podemos pensar as imagens imersivas dos dispositivos VR $360^{\circ}$ como espaços metafóricos e conceituais, lugares habitáveis onde se estabelece um giro que vai deslocar o peso dessas imagens da apreensão de um olhar para a realidade até a experiência do sujeito no real. Nesse sentido, quando os cineastas aplicam esta nova configuração técnica para desdobrar suas produções em espaços esféricos de prospecção imersiva, tem ao seu alcance um instrumento filosófico cuja força reflexiva vai além dos limites da linguagem e da narração literal de histórias. Essa condição outorga aos documentaristas a capacidade de apresentar um jogo de ideias que se coloca em funcionamento através do movimento especulativo que o usuário estabelece com as imagens. O cinema documentário dispõe assim de um dispositivo mais apropriado para abordar a complexa realidade.

O dispositivo VR $360^{\circ}$ apresenta uma forma estética que vem a reformular o termo documentário, já que quando se faz uma plena utilização dos seus recursos, abandona a função clássica-positivista de uma produção objetiva da memória histórica baseada na gestão, descrição e hierarquização do que Foucault (1969) e LeGoff (2005) denominam documento/monumento. Cabe pensar, portanto, numa outra ordem, a do Cinema do Real, uma vez que esse dispositivo de imaginação e conhecimento se constitui como uma ferramenta útil para indagar as múltiplas facetas da realidade. Mas também em sua capacidade para explorar e mostrar suas raízes e os vínculos e relações que se estabelecem com o universo simbólico das imagens. Por consequência, a criação desses ambientes imersivos do real manifesta a possibilidade de mergulhar nas profundezas do assunto tratado e, ao mesmo tempo, informar-nos da relação dialética que se articula entre as formas audiovisuais e a realidade. Como aponta Català (2017), estes ambientes imersivos do real tem a possibilidade de constituir um tipo de "documentário complexo de caráter hermenêutico que não produz documentos nem testemunhas, senão que planteia problemas e procura soluções sobre uma realidade entendida com uma multidão de facetas"(2017, p. 186).

\section{Fenomenologia do esférico nas ecologias visuais do pensamento}

Cada época cria sua própria realidade através de um conjunto de leis, crenças e visualidades que se adaptam à efetividade prática do momento da forma mais conveniente. Na atualidade a forma esférica se destaca como uma poderosa metáfora ontológica que sustenta toda uma série de capacidades expressivas e introspectivas. Por isso, a chegada das atuais imagens imersivas 
da realidade virtual ${ }^{1}$ vem a oferecer uma serie de possibilidades que se ajusta aos requisitos dessa efetiva epistemologia contemporânea relacionada com um tipo de realidade expansiva, móvel, fluida e sem um centro fixo.

Nos dispositivos VR $360^{\circ}$ a existência do sujeito individual é definida ao ampliar nosso campo de visão para uma concepção ambiental da representação. Assim, através de seu ponto de vista holístico sobre o mundo, o espaço surge como uma entidade que se estabelece através das relações entre os diversos elementos do ambiente. Pois, neste dispositivo, supera-se o tradicional ponto de vista da mirada renascentista que, ao estar ordenado de acordo com o modelo de configuração mental da perspectiva, situa os fenômenos como entidades separadas.

Talvez o conceito de nicho ecológico (Umwelt), desenvolvido por Uexküll (1957), possa revelar melhor que a fenomenologia das imagens contemporâneas remete a uma configuração complexa da realidade que excede sua simples leitura como uma manifestação externa ao sujeito. Segundo essa noção o sujeito vive imerso numa esfera particular (ou milleu) através da qual vai se conectando por osmose com os diversos aspectos do ambiente variável que encontra ao seu redor. Quer dizer, nesse espaço a ação do sujeito determina os limites de seu mundo particular a partir do entorno que comparte com os outros. Esta configuração remete à metafísica das substâncias simples que Leibniz (1720) resume em seu tratado sobre as mônadas: "toda substância individual é como um mundo inteiro e como um espelho de todo o universo (...) assim, o universo está de alguma maneira multiplicado tantas vezes como substâncias haja" (Citado em Català, 2017, p. 237). Por tanto, nesses entornos digitais de comunicação virtual os mundos são modelados pelo sujeito e, ao mesmo tempo, o sujeito é modelado reciprocamente pelos mundos com os que interatua. Ou seja, se levamos em conta que nas plataformas visuais contemporâneas a tecnologia e a realidade se encontram estreitamente conectadas, podemos deduzir que é a própria realidade que se molda às características dessa subjetividade tecnificada. Porém, para poder alcançar una concepção verdadeiramente ecológica desses ambientes devemos ter em conta que neles as relações não são lineares, senão expansivas e reversíveis.

O envolvimento esférico do território não se limita a uma esfera só, nesse sentido é oportuno atender ao pensamento topológico de Sloterdijk (2006) quando no ultimo volume de sua trilogia das esferas introduz a metáfora das espumas. Ele propõe que para além da macroeferología dos globos e da microeferología das bolhas a bio-tecnosfera se apresenta como uma esferología plural, um "mundo poliesférico de caráter multifocal onde se estabelecem com-

1. Nesse sentido também cabe destacar as possibilidades acústicas através do som binaural. 
plexas e frágeis inter-relações, carentes de centro e em constante mobilidade expansiva" (Vásquez Rocca, 2008, p. 318). Ou seja, as múltiplas esferas através das quais os sujeitos se trasladam e aglomeram nos entornos da interface se convertem num Umwelt provisório onde se plasma simbolicamente sua particular relação com a realidade. Català sintetiza a proposta de Sloterdijk da seguinte maneira: "Moramos entre bolhas, numa espuma que se forma e deforma constantemente. Não existe portanto uma continuidade superposta aos acontecimentos, senão que estes se supeditam ao espaço-tempo de cada bolha, de cada esfera, de cada ecologia" (Català, 2017, p. 365).

As imagens imersivas contemporâneas têm a capacidade de desenvolver ecologias visuais com as quais o usuário pode se relacionar de uma forma íntima e individual sob um novo regime de complexidade. Assim, como o atributo que determina as atuais representações nas plataformas VR $360^{\circ}$ é sua plena interatividade, entende-se que elas têm a faculdade de se adaptar a cada sujeito variando de forma e inclusive de conteúdo através das relações que o usuário estabelece com elas. Nas imagens esféricas VR $360^{\circ}$, por conseguinte, se propicia uma recomposição do 'eu' a partir de sua situação no espaço relacional, já que, quando o usuário visitante interage com o mundo conceitual representado nesse ambiente visualizado passa a desenvolver uma ação reflexiva com o corpo e com a mente que traz consigo uma composição e decomposição da imagem numa contínua procura por seu significado. Dessa forma, ao encenar seu território imaginário mediante a tecnologia, o sujeito estabelece um processo dialético que agrega percepções, ações e simbolizações. Em outras palavras, se desenvolve um processo de construção do território no qual cada sujeito cria seu próprio ecossistema por meio de uma combinação dinâmica e significativa de tecnologia, ideias e emoções.

Ao converter as emoções estéticas em formas ativadoras de processos reflexivos, essa forma inédita de representação oferece novas possibilidades para aprofundar e compreender a complexa realidade contemporânea. Català já anuncia que não se trata apenas de que "a percepção ambiental nos leve a pensar de forma distinta sobre as representações audiovisuais, mas também que a partir destas novas plataformas de comunicação vamos descobrir novas vias de pensamento sobre a própria realidade" $(2017$, p. 122). De tal maneira que essa plataforma de imagens esféricas só terá um verdadeiro interesse epistemológico se seus valores estão assentados num dispositivo dotado de uma dramaturgia estética onde o sujeito do conhecimento possa estabelecer um processo reflexivo através de um diálogo prático com a realidade e com o próprio dispositivo. 
Portanto, o mote das verdadeiras capacidades das imagens esféricas é submergir o usuário numa cena realista para que possa interagir com seus componentes, ou seja, tornar possível um contato privilegiado com determinados aspectos da realidade através de uma participação ativa com o realismo.

\section{Afeição, movimento e fluidez na montagem do pensamento esférico}

Os documentaristas, ou cineastas do real, ao estabelecerem no design de suas obras estratégias para explorar o potencial que esse novo dispositivo possui, passam a abordar o espaço que se abre entre a teoria e as potenciais práticas de produção e consumo dos entornos digitais imersivos. Nesse sentido, as próprias condições de imediação, hipermediação e remediação que, segundo a nomenclatura de Bolter e Grusin (2000), traz consigo o dispositivo VR, obriga aos criadores destes ambientes a uma reflexão sobre as affordances tecnológicas do meio digital (Gibson, 1977; Norman, 1988; Murray, 2012; Uricchio, 2013; Koenitz, 2015). Na procura de uma narrativa dramatúrgica que atenda à configuração da identidade do operador/ator dessa experiência imersiva, tornase imprescindível abordar questões de usabilidade relacionadas às possibilidades de visão e movimento, empatia, interação e engajamento. Ou seja, qual tipo de estrutura, modos de navegação e estratégias de orientação vão nortear a experiência de acesso e sentido que o sujeito da interação pode estabelecer nesse espaço virtual e fluido para dispor, organizar e, em suma, compreender a realidade do assunto que está sendo abordando.

Boa parte das investigações e aplicações efetuadas no campo das novas formações visuais esféricas é de caráter pragmático, sendo orientada para um realismo estético que procura anular a distância entre os mundos real e virtual. Mas, para além da superficialidade que propõe essa utilização dos sistemas de realidade virtual, existe outra predisposição que procura criar ambientes inteligentes. Nesse caso, a tecnologia não se entende como uma extensão do ambiente para dar sustento a um mundo virtual no qual se introduz o usuário, pois já não é através da representação ou do simulacro que se ativa metaforicamente a realidade. Estamos falando de dispositivos no quais, segundo aponta Català (2017), "os significados têm a dupla virtude de não apenas serem interpretados, mas também atuados através dessa interpretação" (2017, p. 283). De tal maneira que "se desenvolve uma espécie de inversão dessa esfera, ou seja, seu interior se converte num exterior que em vez de se confundir com a própria realidade, confere a ela um significado ativo" (2017, p. 282). Nessa nova ordem, destaca-se o surgimento de dispositivos emocionais nos quais "as sensações são o fator imprescindível para corporizar o ambiente e canalizar subjetivamente o processo de pensamento relacionado a ele" (2017, p. 282). As 
emoções, portanto, incrementam o fator sensação às funções de ação (busca) e percepção (conhecimento) como geradoras do mundo pessoal do usuário que interage com as imagens esféricas.

A construção de sistemas afetivos é o tropo chave para uma prática profunda do cinema do real em sistemas automáticos de Realidade Virtual. Adrian Miles (2014) utiliza o conceito imagem-afecção de Deleuze (2009) para apresentar as possibilidades de interação no documentário como uma heurística produtiva. Assim, através do esquema tripartite percepção, afeto e ação, que o filósofo francês apresenta sob o conceito imagem-movimento, entende que a interação audiovisual que oferecem os entornos digitais produz "ecologias afetivas" (Miles, 2014). Ao mesmo tempo considera que é nos filmes documentários onde se concentra essencialmente o principio da imagem-movimento. Pois, seguindo Nichols (1999), o cinema de não ficção se construí basicamente com argumentos e ideias mais do que com ação, sendo nesse intervalo cogitativo (que separa a percepção e a configuração da resposta) a partir do qual surge um particular tipo de conhecimento afetivo que constitui o valor principal do documentário. Por tanto, esse valor afetivo que permeia as imagens dos documentários manifesta-se através de uma condição indeterminada de admiração e conhecimento que se efetiva fundamentalmente por meio de formas reflexivas, poéticas e associativas. O documentário requer, e se cria, a partir desse intervalo epistemológico, e por isso é inevitável que essas questões constitutivas ganhem uma forma especifica no contexto dos entornos e das práticas de interação imersivas (Miles, 2014, pp. 78-81).

Os usuários que interatuam no interior dessas plataformas através do corpo (movimento) e da visão (observação) exercitam uma operação de montagem (movimento-afeção) que já não remete a um procedimento sintético ou analítico, senão a um deslizamento fluido e efetivo que se fundamenta ao por em contanto objetos (coisas) e pensamento (ideias). As imagens desses entornos modelam simultaneamente o tempo e o espaço desenvolvendo o fluxo de um espaço-tempo visível. Além disso, a submersão no espaço interior de uma imagem volumétrica supõe também experimentar os impulsos de sua exterioridade, já que, quando o espaço contentor se materializa e se visualiza o faz através de uma forma que excede seus limites.

Nesses novos ambientes virtuais que catalisam a paisagem natural e pelos quais circulam corpos reais, propaga-se um modo de reflexão que é a projeção virtual de um pensamento ambiental. Diante dessa configuração é impossível demarcar sua experiência nos limites do pensamento linear e unidimensional, dado que, os fenômenos já não só acontecem na frente do espectador senão ao seu redor. Por isso, é necessário atender às possibilidades do que Català 
denomina como pensamento esférico (2017), pois estamos diante de imagens aparentemente vazias de ação e intenção mas que geram uma concentração emotiva através da combinação e superposição de elementos presentes e passados, reais e imaginários. Isto quer dizer que no ambiente das imagens envolventes ao mesmo tempo que se estabelece uma política dos lugares e das atmosferas também surge uma estética dramatúrgica emocional e cognitiva.

O dispositivo de comunicação VR $360^{\circ}$ abre, portanto, a possibilidade de um renovado horizonte para pensar a realidade e, nesse sentido, temos o desafio de definir a experiência epistêmica e os modos de conhecimento que oferecem as imagens imersivas desses ambientes. Para além das convenções que já foram estandardizadas de acordo com o modo de exposição do conhecimento cinematográfico, é preciso situar o foco de análise nas possibilidades que oferece este dispositivo ao se converter num instrumento de pensamento-ação do sujeito. Ou seja, um dispositivo dotado de uma dramaturgia onde o sujeito do conhecimento possa estabelecer um processo emocional e reflexivo através de um diálogo prático com a realidade e com o próprio dispositivo. Entramos assim no debate sobre qual é o verdadeiro potencial que essas novas tecnologias oferecem para experimentar o real nas ecologias da imagem.

\section{No limiar da metáfora}

A chegada do dispositivo audiovisual imersivo de realidade virtual para consumo doméstico tem produzido um vasto número de propostas criadas por diversos grupos profissionais, como jornalistas, designers de jogos, artistas visuais, ativistas sociais, pesquisadores e cineastas. Muitos produtores e diretores de documentários estão à procura de uma nova gramática que desdobre a linguagem do cinema para se adaptar a esse modelo de experiência audiovisual. Porém, apesar das múltiplas ressonâncias com o cinema, estamos ante um novo dispositivo cujo formato precisa ser elaborado. Trata-se de abandonar as concepções lineares que se encontram na base da montagem clássica cinematográfica e compreender que as narrativas e dramaturgias que articulam as histórias nessas formas visuais estão estruturadas no interior de âmbitos espaciais complexos.

No campo do documentário, muitas das incipientes produções realizadas em VR $360^{\circ}$ nos permitem observar as contrariedades que resultam da aplicação da criatividade e metodologias vinculadas aos parâmetros do cinema. Continuam sendo utilizados recursos de edição, trilha musical, voz off onisciente, intertítulos sincronizados às imagens, e outros elementos que manifestam uma noção desta tecnologia audiovisual emergente pensada como um novo formato de vídeo sem quadro. Esse procedimento supõe ficar no limiar da metáfora que 
propõem as imagens desse dispositivo pois o foco de seu design desvia-se das propriedades que apresenta o espaço diegético VR $360^{\circ}$.

Estou me referindo a propostas como: i) Cloud over Sidra ${ }^{2}$ (2015), um projeto patrocinado pela ONU que acompanha o percurso diário que uma menina Síria de doze anos efetua no campo de refugiados Zaatari na Jordânia, desde a barraca dos seus pais até o laboratório de informática, passando pela escola, a padaria e o campo de futebol; ii) As it is ${ }^{3}$ (2015), um produto produzido por 360Labs que surge com a finalidade de ajudar na preservação do entorno ecológico e social do Parque Nacional do Grand Canyon, oferecendo uma alternativa para aqueles turistas que desejam conhecê-lo; iii) Rio de La$m a^{4}$ (2016), um projeto do cineasta Tadeu Jungle que tem como propósito abordar o rompimento da barragem de Fundão no município de Mariana (MG), um desastre ambiental provocado pela empresa de mineração Samarco que, além de matar 19 pessoas, destruiu a vila de Bento Rodrigues e assolou a bacia hidrográfica do rio Doce; iv) Lions $360^{\circ 5}$ (2017), um curta-metragem produzido pelo National Geographic que conta a história do jovem leão Gibson e de sua mãe, obrigados a abandonar sua manada por causa de um conflito com o novo macho dominante; v) My Africa ${ }^{6}$ (2018), uma inciativa da ONG Conservation International financiada pela fundação Tiffany \& Co. que traz uma visão da vida quotidiana de uma comunidade africana que cuida de seu gado, trabalha na escavação de "poços de canto" nos margens de um rio seco e resgata uma cria de elefante que ficou órfã por causa de caçadores.

No caso dessas produções, a imagem esférica não só se apresenta como uma simples ilustração ilusionista da realidade, ao se fundir com os depoimentos e outras marcas da enunciação elabora um constructo simbólico e social que salienta o reconhecimento empático através dos desejos distintivos e contraditórios inerentes ao paradoxo da retórica cinematográfica. Essa identificação se dá através de estratégias muito diversas, como a apresentação dos limites da liberdade de Sidra, as ações ecobiológicas nos pastos selvagens de Kenya, as vicissitudes que se devem enfrentar para crescer dentro de uma manada, a possibilidade de experimentar uma viagem virtual pelas gargantas do rio Colo-

2. Recuperado de: www.youtube.com/watch?v=FFnhMX6oR1Q. Acesso em 25 de agosto de 2018

3. Recuperado de: www.youtube.com/watch?v=EAHsdMtYmkI. Acesso em 10 de setembro de 2018.

4. Recuperado de: www.youtube.com/watch?v=7zQZqqSkJq0. Acesso em 17 de março de 2018.

5. Recuperado de: www.youtube.com/watch?v=sPyAQQklc1s. Acesso em 24 de julho de 2018.

6. Recuperado de: www.youtube.com/watch?v=119f017sqwg. Acesso em 2 de Setembro de 2018. 
rado, ou as memórias emotivas dos sobreviventes em contraste com a paisagem devastada pelo desastre ambiental.

Seguindo a abordagem de Elisabeth Cowie (2011), consideramos que as imagens destes documentários apontam para o desejo de uma realidade suscetível de revisão e análise: as condições em que vivem os refugiados de conflitos políticos; os impactos e ameaças que supõem a criação de um megaprojeto turístico num parque natural que é Patrimônio da Humanidade; o mundo destruído pela lama de tóxica após o rompimento de uma barragem; as inclementes regras hierárquicas numa manada de leões da savana africana; e a preservação de um modo de vida através da ligação harmônica com a flora e a fauna selvagens. A materialidade dessas realidades se faz evidente e disponível para o conhecimento através da observação e da interpretação empírica da enunciação, mas também transmite-se uma realidade simbólica que é socialmente ordenada e produzida como um significado. Nessa relação, os observadores são integrados por "um discurso de reconhecimento e classificação, num campo densamente constituído de conhecimento, poder e técnicas" (Cowie, 2011, p. 2). Em outras palavras, o ordenamento do espaço simbólico que apresentam esses documentários possui uma parte formal e outra psicológica. Na formal, essa construção simbólica está sempre presente, enquanto que na psicológica é necessário que o destinatário esteja em contato com as crenças e sensações que servem de suporte para ela. A exposição desses relatos identifica o espectador com as problemáticas e personagens através das experiências que estão sendo compartilhadas. Com isso se propõe uma dimensão do conhecimento (e, consequentemente, do saber e do poder), baseada na mobilização e formação do público receptor, o que supõe uma relação de possessão e controle entre aqueles que projetam e dirigem as historias e os que consumem essas narrativas.

A proposta estética que trazem esses documentários pode se definir dentro do arcabouço epistemológico do documentário clássico, no qual a narrativa passa a adquirir uma importância relevante ao se converter numa forma de desvendar verdades através da linguagem cinematográfica. Ou seja, se produz uma apresentação expressiva e simbólica que introduz um procedimento de discussão e pensamento com capacidade para transmitir valores e conceitos mediante a produção de emoções conscientes. Porém, essa forma de representação dirigida à construção de uma narrativa da realidade inevitavelmente esbarra naquilo que Steyerl (2011) denomina "principio de incerteza documental":

Geralmente, a relação com as propriedades do documentário sempre tem sido a de um impasse não reconhecido. Oscila entre a crença e a incredulidade, entre a confiança e a desconfiança, entre a esperança e a desilusão (...) Sempre 
tem se questionado não só se representa a realidade também o modo em que a representa. (Steyerl, 2011, p. 2).

Com relação ao conteúdo, as produções apontadas aumentam nosso grau de conhecimento sobre a realidade que se apresenta, mas a nível formal não se desafiam ou subvertem as categorias que organizam a "verdade" do conhecimento. Ou seja, não se aproveitam os atributos que o dispositivo oferece para perseguir um saber no qual a exposição do conteúdo verdade esteja imbricado à forma discursiva que o desenvolve. Essa propriedade estrutural é uma das potências presentes nesse dispositivo que deveriam contribuir para refundar o meio. Ela surge quando o conhecimento se converte em ativo e deixa de ser o sedimento ideológico inadvertido que controla as atuações e discursos do dispositivo.

A estrutura retórica expositiva que sustenta a enunciação e o modo de representação destes documentários, não consegue desenvolver as possibilidades estéticas e epistemológicas que facilitam as tecnologias VR360 . Nos casos apresentados, se adotamos a abordagem de Machado (2007), entende-se que ainda que os ambientes que aparecem na tela possam ser alterados e redispostos pelo usuário, os processos narrativos de codificação estão definidos a priori segundo a lógica do paradigma cinematográfico. Dessa maneira, para manter a continuidade do argumento, tanto a montagem quanto a perspectiva verbal da voice-over (distante e onisciente) evidenciam as marcas de uma estratégia que se atribui a um sujeito narrador interno à diegese. Com isso, dilui-se a possibilidade que essas tecnologias oferecem para criar um ambiente verdadeiramente imersivo, onde se estabeleça um diálogo recursivo entre o programa de geração automática de situações e as ações exercidas por esse receptor ativo. Esse aspecto é fundamental já que, segundo apontado por Machado:

Cabe a esse programa, senão decidir concretamente o que vai acontecer (uma vez que isso depende também das decisões tomadas pelo interator), estabelecer o universo de eventos permitidos e as condições para que aconteçam. Ele funciona, portanto, como uma espécie de meta-narrador, cuja função primeira é estabelecer as regras e condições para os acontecimentos possíveis no universo diegético, uma vez que as intrigas singulares serão efetivamente produzidas pelo interator que dialoga com o programa. (2007, p. 144).

A disposição destes documentários, portanto, abre possibilidades para que o usuário formule questões sobre o status da representação, o qual possibilita entender o imprevisível, o desconhecido, o ignorado. Porém, o enraizamento da busca narrativa por uma certa verdade impede a possibilidade de alcançar um nível epistemológico construtivo que seja capaz de compreender a complexidade do real situada no âmbito ecológico desse dispositivo. Assim, perde-se 
a possibilidade do sujeito da interação efetuar uma prospecção participativa e, com isso, explorar o atributo múltiplo que detém as imagens imersivas.

\section{Concretizando o sonho da transparência}

Ao longo dos últimos anos, o audiovisual imersivo em formato de vídeo $360^{\circ}$ e a realidade virtual gerada por computador trouxeram múltiplas e inovadoras possibilidades que tem suscitado um rápido interesse em tentar documentar e divulgar as mais variadas experiências com a realidade. Essa grande eclosão de experimentos vão desde a relaxante sensação de desfrutar de uma praia em Virtual Beach ${ }^{7}$ ou da alucinante visão do espetacular fenômeno atmosférico da aurora boreal em Aurora Borealis over Kashwitna Lake ${ }^{8}$, passando pelo assombro de estar a bordo de um avião de combate F/A-18 Hornets em Experience the Blue Angels ${ }^{9}$, pela emoção de se deslizar por um escorregador aquático em Body2Racer Hallenbad Nordost ${ }^{10}$, de saltar de paraquedas em SkyDive ${ }^{11}$, a de pegar carona com Sebastiam Buemi num carro de formula 1 em Red Bull $F 1^{12}$ ou descobrir o que sente um piloto de motoGP ao competir na pista de um circuito com Jorge Lorenzo em Piloto 360 Movistar Yamaha ${ }^{13}$. Olhando para projetos que estão mais engajados com a teoria e a estética do documentário encontramos essa mesma linha de tratamento e construção audiovisual, baseada na observação de fenômenos em situações específicas, na trilogia Nomads: Sea Gypsies, Maasai e Herders ${ }^{14}$. Nela os realizadores canadenses Felix Lajeunesse e Paul Raphael propõem uma série de documentários que tem o intuito de transportar o espectador pelo mundo a partir da realidade de várias culturas nômades.

Um dos fatores principais dessas várias tentativas é o fato de que a ecologia de meios que articula esse formato audiovisual deriva de um cenário onde as estruturas sociais, tecnológicas e econômicas são completamente novas. $\mathrm{Na}$

7. Recuperado de: https://www.youtube.com/watch?v=_hzhtfTqwYo. Acesso em 26 de março de 2018.

8. Recuperado de: www.youtube.com/watch?v=ehJg_OlcjpE. Acesso em 14 de maio de 2018

9. Recuperado de: www.youtube.com/watch?v=H6SsB3JYqQg. Acesso em 15 de abril de 2018.

10. Recuperado de: www.youtube.com/watch?v=QBSImLcbqV8. Acesso em 20 de março de 2018.

11. Recuperado de: www.youtube.com/watch? $\mathrm{v}=\mathrm{S} 5 \mathrm{XX}$ sRuMPIU\&t=228s. Acesso em 6 de maio de 2018.

12. Recuperado de: www.youtube.com/watch?v=wfNvZwN87Hg. Acesso em 15 de maio de 2018.

13. Recuperado de: www.youtube.com/watch?v=KhM4wCxAG8Y. Acesso em 28 de junho de 2018.

14. Recuperado de: www.felixandpaul.com/?projects/sea_gypsies. Acesso em 19 de junho de 2018 . 
conjuntura atual as empresas tecnológicas estão colocando à disposição de produtores e usuários um enorme número de novas plataformas e dispositivos. Nesse sentido, e diferentemente do que aconteceu nos médios anteriores, os usuários estão no centro da formação dos modelos tecnológicos de circulação e aceso, participando ativamente através dos reprodutores de VR $360^{\circ}$ em internet (como o de youtube), e das possibilidades que oferecem as redes sociais (como facebook). Em outras palavras, o baixo custo destes dispositivos (camarás de gravação, óculos, software, etc.) e a proliferação mundial de smartphones fazem possível uma rápida expansão da expressividade humana através desses novos dispositivos, porém essa rápida evolução das tecnologias emergentes podem dificultar na averiguação do que é bom ou ruim do que é simplesmente novo.

A excitação diante das possibilidades dessa nova tecnologia e a confusão nos princípios que traz seu desenho está possibilitando que uma boa parte das imagens esféricas e imersivas baseados no tratamento da realidade, como as citadas acima, estejam promovendo a empatia e o sentido espacial como um valor inerente ao dispositivo VR $360^{\circ}$. Mas, como anuncia Murray (2016), o simples fato de utilizar uns óculos de realidade virtual não necessariamente significa que tenhamos uma melhor experiência de identificação do que diante de uma imagem 2D apresentada na TV ou em formato fotográfico.

Em termos de análise estética podemos dizer que essas propostas partem de uma concepção empírica do real e da capacidade que tem a representação de transportar o usuário para outro lugar e tempo. O que traz consigo a questão do realismo estético, ou seja, da reprodução da realidade através de suas representações ou do valor mimético das representações. Nesse sentido, o conceito de documentário que se projeta nesses trabalhos está alinhado ao "modo de representação observativo", segundo a categorização realizada por Bill Nichols (1999, p. 146), pois neles se propõe uma ação direta para captar a realidade e uma exposição verídica de fatos reais e concretos. Portanto, são propostas que partem do principio da "ontologia da imagem fotográfica", introduzido por Bazin (1991, p. 19), através do qual se reproduz o mundo real na continuidade física dos acontecimentos e na fluidez da ação espacial. Dessa forma se cumpriria o sonho almejado pelo critico e teórico francês, ao alcançar o ponto culminante de um "cinema total" (p. 27) onde a "montagem é interdita" (p. 54). Por conseguinte, esses trabalhos trazem uma proposta que assume o processo naturalista de representação através de uma forma que busca aparentar transparência e denotação direta para objetivar o representado. Para apreender e organizar a realidade tal como ela é esses "documentos do real" adotam um marco epistemológico no qual o elemento fundamental é a câmera. Através 
da câmera se alcança o conhecimento de um mundo que aparece como foco e início da experiência verdadeira do sujeito.

Se transpomos esse modelo gnosiológico à nomenclatura das fases que apresenta Català (2016) para articular a história da cultura podemos considerar que sua forma de representação se corresponde com o tipo de documentário moderno (ou da modernidade). No entanto, e seguindo as apreciações de Cassirer (1972), entendemos que cada época cria suas próprias formas simbólicas, pois, no símbolo, produz-se uma "síntese do mundo e do espírito" (1972, p. 57). Ou seja, as formas simbólicas que expõem os dispositivos tecnológicos, desde a roda primitiva até as interfaces VR, projetam materialmente em primeiro termo uma série de conteúdos paradigmáticos dos modelos mentais que permanecem no fundo do pensamento daquela conjuntura social.

$\mathrm{Na}$ fase atual, segundo indica Flusser (2008), a "escalada da abstração" alcançou um modelo epistemológico de ordem pós-histórico, o que deixa os criadores desses documentários ancorados no paradigma referencial da imagem representativa que, como indica Machado (2007, p. 137), trouxeram os aparelhos que sistematizaram a perspectiva de projeção central na época do Renascimento (o intersector de Alberti, a tavoletta de Brunelleschi, a tela quadriculada de Dürer etc.). Nesse sentido, entendemos que a aplicação das tecnologias VR $360^{\circ}$ como qualidade de conhecimento da realidade estaria seguindo o mesmo caminho realista que tomou a fotografia no começo do século XIX. Isto é, "redescobrir" como marco epistemológico as técnicas de codificação ótica e geométrica que a perspectiva renascentista utilizou para automatizar parcialmente o processo pictórico. Com isso, se está revelando uma forma simbólica na qual, como diz Couchot, citado por Machado (2007), o sujeito é aparelhado (le sujet appareillé) ao depender "fortemente de uma máquina que realiza boa parte das operações de ver e representar" (p. 137). Esse sujeito aparelhado ou sujeito-SE, segundo a própria conceptualização que Couchot toma de Merleau-Ponty, "passa a funcionar sob um modo indefinido, impessoal e anônimo" (p. 137) cuja experiência de subjetividade "não deriva de uma vontade, de um desejo, de uma iniciativa, de um lapso de sujeito constituído (ainda que ausente), mas dos automatismos do dispositivo técnico" (p. 136).

O sujeito-SE que se invoca na experiência destas propostas de interação com o real responde a um fazer técnico estruturante cuja enunciação, ainda sob a perspectiva de Arlindo Machado, já não é mais "um inconsciente psíquico, imponderável e polissêmico, mas uma espécie de inconsciente maquinal, multiforme mas delimitado e programado" (2007, p. 138). Dessa forma, entendemos que a utilização que esses trabalhos fazem do dispositivo VR $360^{\circ}$ é muito reduzida. Pois, se limitar ao sujeito a utilizar o aparato sem tomar 
verdadeira consciência do mesmo o usuário não estará pensando através desse dispositivo, pelo contrário, estará sendo pensado por ele. No entanto, a necessidade dessa tomada de consciência não anula automaticamente a condição subordinada do sujeito, porque embora ele se torne a razão plena do ato da figuração também se apaga, perde sua função e, de alguma maneira, se converte numa espécie de sujeito-máquina. Contudo, a possibilidade de diálogo com o aparato sempre existe, numa ou em outra direção.

Portanto, o desafio que propõe o dispositivo VR $360^{\circ}$ aos criadores audiovisuais é tentar impulsionar a conversa a partir do operador até a máquina, para lograr que esta proceda em favor do pensamento-ação do sujeito, e não que sejam os elementos do dispositivo que façam demandas ao operador, tornando-o um instrumento de sua razão técnica.

\section{Alegorias no Pensamento Esférico}

As imagens geradas pelo dispositivo VR $360^{\circ}$ permitem representar e compreender essa mudança de paradigma que atinge às transformações do visível através de um entorno esférico onde os objetos e o sujeito se transformam num fluxo constante. Porém, é importante salientar que as tecnologias não são a causa direta das mudanças da realidade, nem constituem a estrutura ou arquitetura sobre a qual a realidade se sustenta. As tecnologias surgem para dar resposta às demandas da realidade e ao mesmo tempo são ferramentas hermenêuticas que permitem investigá-la. Por isso, para se aproximar à realidade fundamental do Real, também é necessário decifrar as tecnologias e a melhor maneira de fazê-lo é através de uma atividade de interação reflexiva com as imagens técnicas que elas produzem.

Os distintos aparatos e plataformas deste dispositivo vão proceder em prol da apreensão dessa realidade fundamental quando desenvolvem projetos que propõem uma alternativa ao realismo referencial que carrega a imagem documental. Essa procura estilística dos autores passa por destilar formas expressivas capazes de revelar um modo de pensamento-ação no sujeito que interage com a obra, mas também por adaptar os fundamentos da encenação e dramatização que aquilatam os distintos meios correlacionados a este dispositivo. A partir disso, para desenvolver plenamente esse dispositivo é importante assimilar ideias, fundamentos e modos de exposição desenvolvidos pelas correntes estéticas e narrativas das artes da representação: pintura, literatura, teatro, música, opera, circo, dança, fotografia, cinema, quadrinhos, animação, vídeo-arte, arte interativa, etc. Isso, como já ficou demostrado, não passa por evidenciar as virtudes desses meios expressivos, e sim por adotar sua influência epistemológica para que, ao trabalhar desde a perspectiva da criação de metáforas 
habitáveis, possam gerar distintas formas de entender as condições da existência humana e social.

A partir dessa perspectiva que explora o dispositivo VR $360^{\circ}$ com imagens hibridas e complexas que oferecem ao sujeito possibilidades de pensamentoação, encontramos propostas que se destacam: Clouds $^{15}$, Drawing room ${ }^{16}$, Notes on blindess ${ }^{17}$ (Arnaud Colinart e Amaury La Burthe, 2016), La vampira del Raval ${ }^{18}$, Zero Days VR ${ }^{19}$.

Estas obras expõem temáticas e formas de tratamento muito diversas mas o fundamento de suas imagens coincidem ao operar com a realidade desde uma perspectiva excêntrica, na qual o usuário da interação se situa num plano psicofísico que estimula uma transformação na sua própria maneira de pensar o mundo. Para além dos diversos nexos que se estabelecem com os personagens e suas respectivas percepções o indicador comum dessas propostas é que nelas os indivíduos constituem-se a si mesmo a partir de sua situação no território e da relação que estabelecem com o ambiente que estão explorando. Todos esses projetos fazem uma utilização do dispositivo VR360 que transcende o marco clássico e moderno do documentário porque são propostas que situam o espectador num espaço de reflexão onde se pensa a imagem, pensa-se com a imagem e a imagem pensa.

No caso de Drawing room o autor e ilustrador Jan Rothuizen foi convidado pela loja de departamentos mais antiga de Amsterdam (De Bijenkorf) para achar inspiração e criar desde o quarto que fica no telhado da torre central do prédio, que está situado numa área central da cidade. Nesta obra ele apresenta a possibilidade de experimentar esse privilegio através do que define como uma realidade desenhada (drawn reality). Pois essa vivencia, além de oferecer ao usuário a oportunidade de avistar a cidade e a movimentação das pessoas que transitam pela praça Dam Square, passa também por se questionar sobre como a experiência de estar em algum lugar pode ser uma obra de arte em si mesmo. Para isso o autor coloca em imagens uma realidade na qual o real e o irreal se fundem numa estratégia de pensamento-ação. Nesse âmbito de reflexão o simples ato de olhar não concede nenhum conhecimento imediato, senão que é preciso explorar esse espaço para assimilar as observações afiadas de Rothuizen que estão esparramadas alegremente pela tela virtual.

15. Recuperado de: https://cloudsdocumentary.com/_-_info. Acesso em 23 de maio de 2018.

16. Recuperado de: www.youtube.com/watch?v=V6a3QIFOeYs. Acesso em 15 de abril de 2018.

17. Recuperado de: www.notesonblindness.co.uk/vr/. Acesso em 9 de maio de 2018.

18. Recuperado de: http://lavampiradelraval.com/es/vr. Acesso em 2 de abril de 2018.

19. Recuperado de: www.oculus.com/experiences/rift/1021742081285760/. Acesso em18 de abril de 2018. 
Na obra Zero Days $V R$ a experiência dos usuários é conduzida para o mundo invisível de guerra cibernética através da perspectiva do vírus Stuxnet, que é a primeira arma cibernética conhecida por causar um dano físico real no mundo. O espectador acompanha o fluxo da missão clandestina desse vírus incubado pelos EEUU e Israel para sabotar uma instalação nuclear subterrânea Irani. Nesse percurso, o território se subjetiva e torna-se psíquico enquanto o processo mental se materializa e torna-se físico. Dessa forma o usuário, ao estar situado no lugar do vírus, passa a pertencer à obra mas a obra também lhe pertence, pois o corpo pensante se funde com o ambiente simbolizado ao experimentar o alto risco da guerra cibernética na escala humana. Para que o usuário assimile plenamente a experiência territorial que se oferece nesse ambiente narrativo não basta tentar decodificar seu significado aplicando os procedimentos do pensamento binário e linear, senão que é preciso evocar uma forma de pensar global e complexa. Ou seja, um pensamento ecológico e reflexivo que não esteja só pautado pelos elementos representados, mas também pela relação que se estabelece entre os elementos representados e a atmosfera que os contém, neste caso o meio destrutivo dos vírus dos computadores.

Essa atividade reflexiva, de alguma forma, pode se relacionar com o processo de territorialização e desterritorialização imaginária dos corpos e coletivos da enunciação social que Deleuze e Guattari conceituaram como geofilosofía (1992). Em Clouds, por exemplo, os usuários podem explorar desde diferentes perspectivas a interseção que se estabelece entre o código e a cultura através dos depoimentos de mais de 40 artistas, designers, hackers e pensadores que emergiram colaborando na internet para inventar tecnologias de acesso público que foram as bases fundacionais da cultura criativa global. Os entrevistados debatem sobre os desafios de desenvolver formas de expressão que repercutem a um nível humano profundo, o diferencial é que seus argumentos podem ser intercalados ilustrativamente com sistemas visuais através de módulos gráficos adicionais. Cada sequência de diálogo pode ser gerada ao executar entradas interativas em tempo real, pois cada uma das entrevistas tem sido editadas em fragmentos individuais e marcados amplamente com tags. Um algoritmo provoca o salto entre as imagens para criar uma nova conversação improvisada mas na qual se preserva a contiguidade de ideias e temas. Os usuários usam o gesto e as metáforas de interação visuais para efeituar um percurso epistemológico pelo espaço dessas imagens. Assim, ao incitar nos usuários um processo mental rizomático, essa ação perceptiva e cognitiva permite um melhor discernimento sobre a complexa realidade cultural contemporânea. Essa forma de criação estética (orientada por dados motorizados que apresenta una conversação sem fim em constante mudança) serve para apurar 
um processo de construção do território onde o político não é uma ação social direta sobre o espaço, e sim o resultado de uma ação desenvolvida conforme os parâmetros do espaço social da realidade. Em consequência, o que está se propondo é que a forma estética pode ser política, mas para isso é preciso que a tensão criativa que promove e arquiteta esses espaços explore em profundidade as coordenadas básicas do próprio dispositivo.

As imagens esféricas dos projetos citados expandem o documentário para o Real através da ação reflexiva de um gesto que combina o movimento corporal com o mental. Esse efeito, onde o material se converte em simbólico e o simbólico em material, se consegue porque os autores partem de um espaço efetivo e factual, mas utilizam uma série de recursos (luz mutante, fusões visuais, motion-graphics, som binaural, imagens 3D, algoritmos para visualização de dados, etc.) que apelam às emoções para convertê-lo num entorno imaginário onde é possível vivenciar uma experiência onírica.

Essa proposta de se aproximar ao real através de um espaço de comoção afetiva e delírio é notória em La vampira del Raval. Nesta obra o visitante é testemunha de uma investigação ao redor da lenda popular de Enriqueta Martí, acusada no começo do século XX de ser uma assassina em série de crianças. Sua história foi considerada pela imprensa como um dos casos criminais mais sórdidos na história da cidade de Barcelona, mas publicações recentes afirmam que o caso estava cheio de imprecisões e declaram sua inocência. A partir do espaço realista da cela onde a protagonista esteve detida e mediante a reconstrução de entrevistas, material de arquivo, e elementos de animação, o documentário propõe uma narração espacial dividida em quatro atos, na qual o espectador se inclui como um agente ativo cujos movimentos destapam informações valiosas para tirar conclusões decisivas sobre o litígio. O realismo sensorial e melodramático desse cenário se converte no personagem principal por onde os protagonistas aparecem de forma circunstancial e fantasmagórica. Assim, através de uma associação anacrônica, como a que Warburg utiliza no seu "Atlas Mnemosine" (2010), se alcança uma dimensão espectral onde as imagens detêm uma espécie de energia rítmica. A pulsão de repetição do "Pathosformel" recompõe sensivelmente o que sobrevive ("Nachleben") daquela época mas que tinha se perdido no decorrer da cadeia de transmissão imitativa forjada ao redor da lenda popular da vampira. A experiência que imprime essa supervivência onírica permite pensar na imagem VR $360^{\circ}$ como um ente heurístico que supera a polaridade estabelecida entre sua tendência à fixação como imago e sua irreprimível disposição ao movimento. Dessa forma, o gesto reflexivo que ritma este vaivém entre o que cristaliza e o que desloca na memória dos usuários suscita uma recomposição sensível que, ao atravessar 
fulgurante a Historia da Vampira, estabelece um contato inédito entre o tempo imediato e o tempo remoto.

A experiência espectral e anímica que geram as narrativas cenográficas apresentadas revelam o caráter alegórico que possuem as imagens quando se estabelecem relações indissociável entre a forma e o conteúdo a partir do próprio território visual. Pois, como indica Català (2012), o sujeito se situa num "nível superposto à imagem literal ou realista", ou seja, produz-se "una reconversão das imagens em formações mentais de caráter simbólico que reconfiguram o representado" (2012, p. 74). No caso de Notes On Blindness: Into Darkness, essa formação alegórica das imagens está em primeiro plano, já que, os autores utilizam as possibilidades narrativas e dramatúrgicas do dispositivo VR360 para explorar a experiência cognitiva e emocional da cegueira a partir dos diários gravados em áudio pelo escritor e teólogo John Hull. Isto é, cada uma das seis cenas da obra abordam uma memória, um momento e uma localização específica de seu diário e, para isso, utilizam recursos narrativos, mecânicas de jogabilidade, som binaural e animações 3D em tempo real que ajudam a criar uma experiência imersiva plena num mundo que vai além da visão. De forma que, para apresentar esse testemunho de perda, renascimento e renovação que John Hull documenta quando ele fica completamente cego, o dispositivo VR $360^{\circ}$ traz consigo uma dramaturgia conceitual e sensorial que efetiva uma reconfiguração alegórica do campo diegético. Ou seja, a adaptação que se realiza dos diários para que o usuário possa experimentar como Hull acha um sentido à vida nesse momento de convulsão não passa por uma representação através de historias narradas, senão utilizando uma serie de recursos audiovisuais para configurar uma aproximação ao real estado do seu mundo interior.

As representações visuais dos documentários avaliados neste epigrafe configuram territórios provisórios onde se apresentam formações e relações diferentes em função da interpretação singular de cada usuário. A verdade, portanto, passa a se transformar no conhecimento reflexivo de uma subjetividade heterogênea, e a estética, na epifania de um pensamento que penetra nas coisas, estabelecendo uma ponte efêmera entre o geral e o particular, entre o subjetivo e a história, entre o pensamento e o sentimento.

\section{Conclusões}

O desenvolvimento das tecnologias VR360 estão em um estágio incipiente e ainda não tem se formado uma narrativa dramatúrgica específica que determine sua aplicação no âmbito do documentário. Nessa busca, entendemos ser fundamental configurar as imagens desse dispositivo como ambientes de cará- 
ter metafórico onde se propicie uma ação reflexiva psico-corporal que revele a possibilidade de exercitar um modo de pensamento adaptado aos requisitos que pautam a realidade contemporânea. Em outras palavras, o audiovisual imersivo em formato de vídeo 360 permite uma possibilidade de mise-en-scène esférica onde o sujeito da interação assume uma função subjetiva e emocional que transcende a representação de uma ideia sobre a realidade e oferece a possibilidade de pensar sobre as múltiplas facetas dessa realidade.

Para explorar as possibilidades práticas desse dispositivo as imagens esféricas precisam configurar uma determinada constelação relacional, heterogênea e complexa, de elementos co-determinantes, com ampla capacidade de afecção. A força desses ecossistemas dinâmicos deve estar disseminada numa multiplicidade de pequenos processos de ação através dos quais o sujeito da interação viva uma experiência transformadora e assuma a consciência de si mesmo como um modo suplementar de conhecimento.

A forma interface que desenvolve o VR360 encontra na transcendência do documentário contemporâneo um dispositivo epistemológico para abordar a complexa disposição da realidade na atual sociedade mediada pelas tecnologias da comunicação. O documentário, ao se expandir para o real, apresenta-se como uma plataforma de imaginação e conhecimento apropriada para efetivar o potencial cognitivo e epistemológico dessas tecno-ecologias visuais. Para isso é preciso que seu modo de exposição do conhecimento adopte a forma vanguardista de uma hipercena híbrida que não trate de reproduzir uma realidade já dada para exercer uma crítica social ou política. Atender e ativar as qualidades desse novo paradigma no qual a realidade se liquidifica passam pelas possibilidades do documentário de adotar uma forma alegórica que consiga expor os matizes dessa realidade.

\section{Referências Bibliográfica}

Bazin, A. (1991). O cinema- ensaios. São Paolo, Brasil: Editora brasiliense.

Bolter, J. \& Grusin, R. (2000). Remediation: Understanding New Media. Cambridge (MA), EEUU: The MIT Press.

Calogero, L. (2016, março). Thinking in paradoxes: The more virtual it is, the more real it is. $i$-Docs 2016. Panel: The promise of VR for non-fiction storytelling. Idocs, Bristol. Recuperado de: http/::i-docs.org:2016:06:29: idocs-2016-panel-promise-vr-non-fiction-storytelling:\%5D \%5B. Acesso em 20 de fevereiro de 2018.

Cassirer. E. (1972). Filosofía d las formas simbólicas. México DF, México: Fondo de Cultura Económica. 
Català, J. M. (2010). La imagen interfaz. Bilbao, España: Servicio Editorial de la Universidad del País Vasco.

Català, J. M. (2012). Guia de perplejos. El cine imposible de León Siminiani. In V. Fernandez \& M. Gabantxo (eds.), Territorios y Fronteras: experiencias documentales contemporâneas (pp. 71-86). Bilbao, España: Servicio Editorial de la Universidad del País Vasco.

Català, J. M. (2016). Documental expandido. Estética del pensamiento complejo. [master class]. In Master en teoría y práctica del documental creativo de la Universidad Autónoma de Barcelona (UAB). Barcelona. Recuperado de: https://vimeo.com/uabmasterdoc. Acesso em 15 agosto 2018.

Català, J. M. (2017). Viaje al centro de las imágenes: Introducción al pensamiento esférico. Santander, España: Shangrila Ediciones.

Cowie, E. (2011). Recording Reality, Desiring the Real. Minneapolis and London: University of Minnesota Press.

Deleuze, G. \& Guattari, F. (1992). O que é a filosofía?. Rio de Janeiro, Brasil: Coleção TRANS.

Deleuze, G. (2009). A imagem-movimento Cinema 1. Lisboa, Portugal: Assírio \& Alvim.

Emmerick, M. C. (2008). Arqueología da interface: visão, gesto, memória e as regras dos jogos dos símbolos. Tese de Doutorado em Comunicação, Universidade Federal Fluminense, Niteroi (RJ), Brasil.

Flusser, V. (2008). O universo das imagens técnicas: Elogio da superficialidade. São Paulo, Brasil: Annablume.

Foucault, J. (1969). La Arqueología del Saber. Buenos Aires, Argentina: Siglo XXI.

Gaudenzi, S. (2013). The Living Documentary: from representing reality to co-creating reality in digital interactive documentary. Tese de Doutorado em Comunicação, University of Goldsmiths, Londres, UK.

Gibson, J. J. (1977). The Theory of Affordances. In R. Shaw \& J. Bransford (ed.), Perceiving, Acting, and Knowing (pp. 67-82). Lawrence Erlbaum.

Koenitz, H. (2015). Towards a specific theory of interactive digital narrative. In H. Koenitz, G. Ferri, M. Haahr, D. Sezen \& T. I. Sezen (eds.), Interactive Digital Narrative (pp. 91-105). Routledge: New York.

Le Goff, J. (1995). A Historia nova. São Paulo, Brasil: Martins Fontes.

Machado, A. (2007). O sujeito na tela. São Paulo, Brasil: Paulus. 
Manovich, L. (2001). The language of new media. Cambridge: MIT Press.

Miles, A. (2014). Interactive Doumentary and Affective Ecologies. In K. Nash, C. Hight \& C. Summerhayes (eds.), New documentary ecologies: emerging platforms, practices and discourses (pp. 67-83). Londres, Reino Unido: Palgrave Mcmillan.

Murray, J. H. (2012). Inventing the medium: principles of interaction design as a cultural practice. Cambridge (MA), EEUU: MIT Press.

Murray, J. H. (2016). Not a Film and Not an Empathy Machine. Disponível em: https://immerse.news/not-a-film-and-not-an-empathy-machine-48b6 3b0eda93

Nichols, B. (1999). Introdução ao Documentário. Campinas (SP): Papirus.

Norman, Donald A. (1988). The Design of Everyday Things. New York, EEUU: Doubleday.

Parente, A. (2007). Cinema em trânsito: do dispositivo do cinema ao cinema do dispositivo. In M. Penafria \& I. M. Martins (eds.), Estéticas do digital: Cinema e Tecnologia. Covilhã, Portugal: Livros LabCom.

Sloterdijk, P. (2006). Esferas III: Espumas. Esferología plural. Madrid: Siruela.

Uexküll. J. A. (1957). Stroll Through the Worlds of Animals and Men: A Picture Book of Invisible Worlds. In C. H. Schiller, Instinctive Behavior. New York: International Universities Press.

Uricchio, W. (2013). Playing with narrative. MIT Open Documentary Lab Research Forum. Disponível em: http://opendoclab.mit.edu/category/resear ch-forum.

Vásquez Rocca, A. (2008). Peter Sloterdijk: Espumas, mundo poliesférico y ciencia ampliada de invernaderos. Nómadas, (18/2): 315-322. Madrid.

Warburg, A. (2010). Atlas Mnemosyne. Madrid: Akal.

\section{Filmografía}

As it is (2015), de Thomas Hayden.

Rio de Lama (2016), de Tadeu Jungle.

Lions $360^{\circ}$ (2017), de National Geographic.

My Africa (2018), de Conservation international, Passion Planet, Vision3.

Cloud over Sidra (2015), de Gabo Arora and Chris Milk.

Virtual Beach (2016), de Acerting Art. 
Aurora Borealis over Kashwitna Lake (2016), de Nature Relaxation Films.

Experience the Blue Angels (2015), de USA Today.

Body2Racer Hallenbad Nordost (2017), de Tuberides.

SkyDive (2015), de vr360 pro.

Red Bull F1 (2015), de VIEMR.

Piloto 360 Movistar Yamaha (2015), de Movistar España.

Nomads: Sea Gypsies, Maasai e Herders (2016), de Felix \& Paul Studios.

Clouds (2014), de Jonathan Minard e James George.

Drawing room (2015), Jan Rothuizen e Sara Kolster.

Notes on blindes (2016), de Arnaud Colinart e Amaury La Burthe.

La vampira del Raval (2016), de Jimena Tormo.

Zero Days VR (2017), de Elie Zananiri e Yasmin Elayat. 